\title{
AiMT
}

Advances in Military Technology

Vol. 12, No. 1 (2017), pp. 33-47

ISSN 1802-2308, eISSN 2533-4123

DOI 10.3849/aimt.01160

\section{Current Capabilities of Modal Analysis of Aircraft Propeller in ANSYS Mechanical Environment}

\author{
R. Vysoký* \\ TechSoft Engineering Ltd., Czech Republic
}

The manuscript was received on 3 November 2016 and was accepted after revision for publication on 26 February 2017.

\begin{abstract}
:
The article deals with the modal analysis of a small aircraft propeller. In here are discussed the possible three cases of the Finite Element Method (FEM) simulation, in the environment of ANSYS Mechanical software. Successively each of them is described by the theoretical and application parts. Further on, there are explained the important results from the modal analysis, i.e., the calculated natural frequencies, mode shapes, participation factors and effective masses. The following three cases of the FEM simulation were used: the classic approach, the cyclic symmetry modelling and the Component Mode Synthesis (CMS) method. At the end the calculated frequencies of the all three cases are compared.
\end{abstract}

\section{Keywords:}

aircraft propeller, ANSYS, CMS, cyclic symmetry, dynamics, FEM, modal analysis

\section{Introduction}

The main aim of this article was to demonstrate the three ways how to perform modal analysis applying the Finite Element Method. For this purpose, the ANSYS system was used in the customary extend. These methods were applied on an aircraft propeller, in order to discover its interesting dynamic behaviour. The knowledge of the propeller dynamics is necessary to ensure the sufficient safety of its power unit, i.e., without resonances during the engine operation [1]. The modal analysis can be applied either on the complete propeller assembly, or on the cyclic symmetry segment of the propeller and also by means of the Component Mode Synthesis method. Usually the computational simulation is carried out at the beginning of development of any modern aircraft propeller. The verification of the aircraft propeller dynamic behaviour in a fact is usually performed by the help of ground testing facilities, where the method of experimental modal analysis is used in most cases. The specialists of VZLU in Prague, i.e., ARTE

\footnotetext{
* Corresponding author: TechSoft Engineering Ltd., Na Pankráci 322/26, CZ-140 00 Prague, Czech Republic, Phone: +420 7770805 20,E-mail: vysoky@techsoft-eng.cz
} 
(Aeronautical Research and Testing Establishment, Prague) take advantage of French measuring instrument PRODERA.

\section{Modal Analysis of Aircraft Propeller}

\subsection{Theory of Modal Analysis}

The modal analysis is the most fundamental of all dynamic analyses and it is recommended to perform this at the first time before others (harmonic, transient, spectrum or random). This technique is used to determine vibration behaviour of structure and it covers natural frequency, mode shape, mode participation factor, effective mass and modal stress distribution. The general equation of motion is referred to in this known form [2]:

$$
[\boldsymbol{M}]\{\ddot{u}\}+[\boldsymbol{C}]\{\dot{u}\}+[\boldsymbol{K}]\{u\}=\{\boldsymbol{F}(t)\} .
$$

Here $\boldsymbol{M}, \boldsymbol{C}, \boldsymbol{K}$ represent mass, damping and stiffness matrices, $\boldsymbol{F}$ constitutes external force, $u$ and its derivation represent displacement, velocity and acceleration.

Then the simplified linear equation of motion for free and undamped vibration is as follows:

$$
[\boldsymbol{M}]\{\ddot{u}\}+[\boldsymbol{K}]\{u\}=\{0\} .
$$

If harmonic motion is assumed:

$$
\begin{gathered}
\{u\}=\left\{\phi_{i}\right\} \sin \left(\omega_{i} t+\theta_{i}\right), \\
\{u\}=-\omega_{i}^{2}\left\{\phi_{i}\right\} \sin \left(\omega_{i} t+\theta_{i}\right) .
\end{gathered}
$$

Substitution $\{u\}$ and $\{\ddot{u}\}$ in the governing equation gives an eigenvalue equation:

$$
\left([\boldsymbol{K}]-\omega_{i}^{2}[\boldsymbol{M}]\right)\left\{\phi_{i}\right\}=\{0\} .
$$

Then let determinant equals zero and eigenvalue problem is solved by:

$$
\operatorname{det}\left([\boldsymbol{K}]-\omega_{i}^{2}[\boldsymbol{M}]\right)=\{0\} \text {. }
$$

The roots $\omega_{i}^{2}$ of this equation represent eigenvalues, which are the square of the natural circular frequency of the structure $\omega_{i}$. Each root has corresponding eigenvector $\phi_{i}$, which means mode shape.

Other two important vibration characteristics constitute participation factor and effective mass.

The participation factor $\gamma_{i}$ is calculated by:

$$
\gamma_{i}=\left\{\phi_{i}\right\}^{\mathrm{T}}[\boldsymbol{M}]\{D\} .
$$

Here $\{D\}$ is an assumed unit displacement spectrum in each of the global Cartesian directions and rotation about each of these axes. This measures the amount of mass moving in each direction for each mode. A high value in a direction indicates that the mode will be excited by forces in that direction.

The effective mass $M_{\mathrm{eff}, i}$ is calculated by:

$$
M_{\mathrm{eff}, i}=\gamma_{i}^{2}, \quad \text { if }\left\{\phi_{i}\right\}^{\mathrm{T}}[\boldsymbol{M}]\left\{\phi_{i}\right\}=1 .
$$

Ideally, the sum of the effective masses in each direction should equal total mass of structure, but it will depend on the number of extracted modes. 


\subsection{Modal Analysis of Aircraft Propeller Assembly}

The geometrical model represented a three-bladed propeller for general aviation. The full assembly of an aircraft propeller was simplified in Space Claim Direct Modeler (SCDM) software. Many features from real geometry were removed for insignificant influence on dynamic characteristics and for easier contact and mesh creation. Consequently, FE (Finite Element) model was built in Workbench Mechanical. The view of FE model is in Fig. 1. The FE mesh was uniform with adequate refinement (element edge size $10 \mathrm{~mm}$ ) and was created by parabolic tetrahedrons SOLID187 (181921 nodes and 106092 elements). The surface contact was formed by pairs of special elements TARGE170 and CONTA174. The suspension was made by means of spring-damper element COMBIN14.

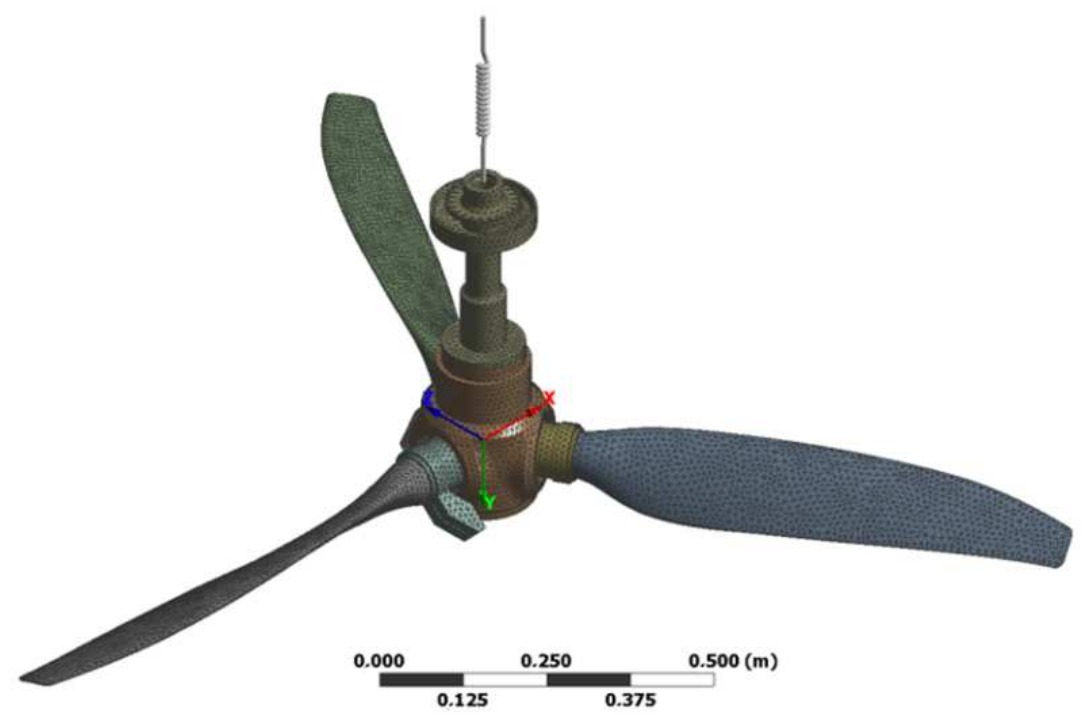

Fig. 1 FE model of aircraft propeller assembly

The aircraft propeller assembly was composed of three blades, three retainers with counterweights, hub and shaft. FE model was hung on spring with longitudinal stiffness $1100 \mathrm{~N} / \mathrm{m}$, so-called free - free Boundary Conditions (BC). All material models were linear isotropic at room temperature. The material of blades and hub was duralumin (density $2770 \mathrm{~kg} / \mathrm{m}^{3}$; modulus of elasticity $72 \mathrm{GPa}$; Poisson's ration 0.33 ). Retainers with counterweights and shaft were made from constructional steel (density $7730 \mathrm{~kg} / \mathrm{m}^{3}$; modulus of elasticity $210 \mathrm{GPa}$; Poisson's ration 0.3 ). Total weight of propeller assembly was $47.2 \mathrm{~kg}$ and the blade weighs approximately $5 \mathrm{~kg}$. The diameter of propeller disc was $1.830 \mathrm{~m}$. The propeller was in pusher configuration and the blade angle corresponded with flight regime.

All fixed connections were used via bonded Multi-Point Constraint (MPC) algorithm, because this works reliably, almost like rigid connections. It covered the following connection pairs specifically: blade vs. retainer, retainer vs. hub and hub vs. shaft. Fig. 2 presents particular contact pairs between geometrical parts and Fig. 3 presents applied Constraint Equations (CE), which defined linear dependence between Degrees Of Freedom (DOFs) of connected nodes of joined parts. 


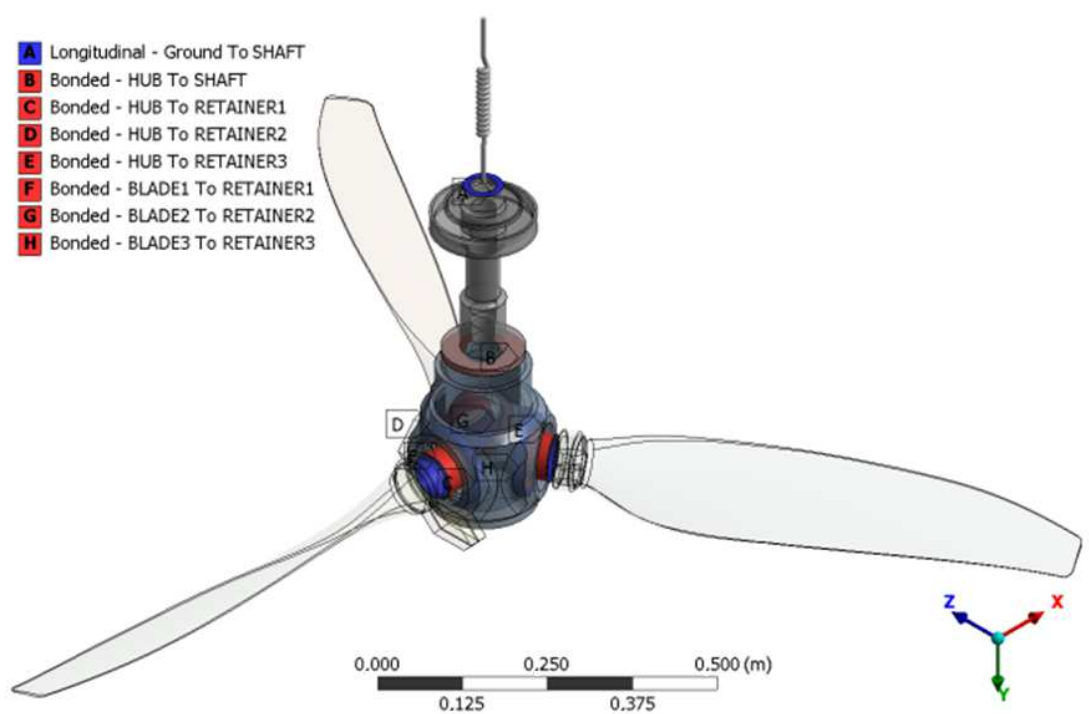

Fig. 2 Contact overview of aircraft propeller assembly

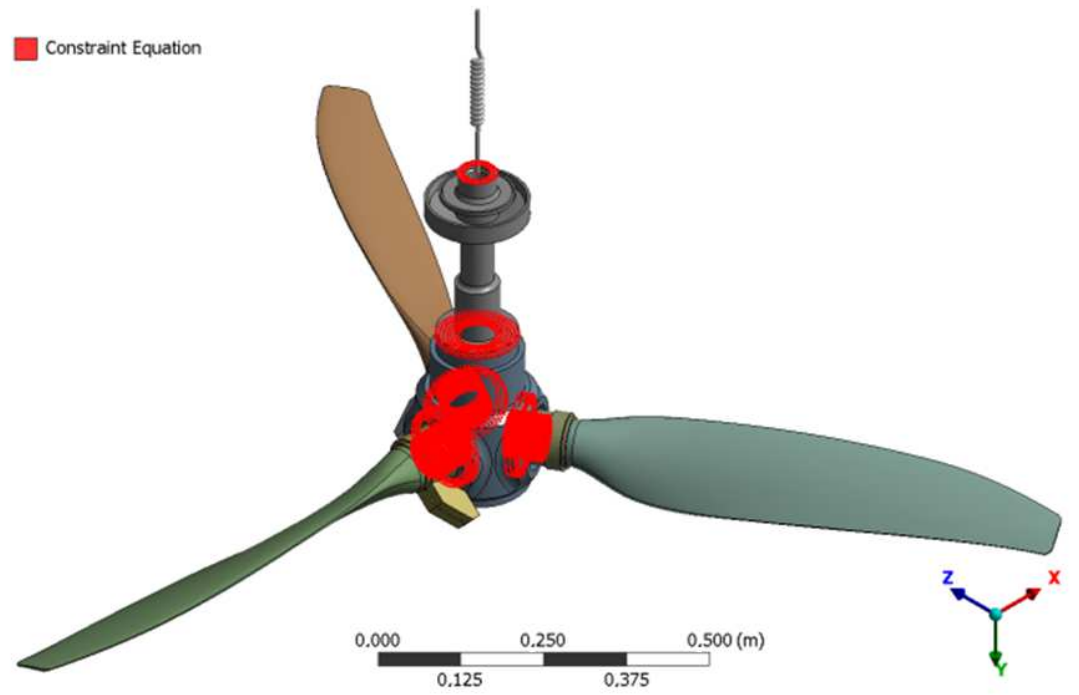

Fig. 3 Constraint equations in aircraft propeller assembly

The built FE model was tuned according results from Experimental Modal Analysis (EMA) [3]. The final comparison of frequency values was documented in Tab. 1 and in Fig. 4. The explanation of second column in the table is following: the number means sequence of mode shape, the abbreviation SF/NF means synchronous/non-synchronous flexure mode of blade and the abbreviation ST/NT means synchronous/non-synchronous torsion mode of blade. The maximal frequency deviation $\Delta f$ between EMA and FEA for synchronous vibration (symmetrical mode shapes) was determined below $7 \%$ and for non-synchronous vibration (non-symmetrical mode shapes) was determined below $11 \%$. 
Tab. 1 Natural frequencies of aircraft propeller assembly

\begin{tabular}{|c|c|c|c|c|}
\hline $\begin{array}{c}\text { Mode } \\
\text { No. }\end{array}$ & $\begin{array}{c}\text { Mode } \\
\text { Shape }\end{array}$ & $\begin{array}{c}f[\mathbf{H z}] \\
\text { EMA }\end{array}$ & $\begin{array}{c}\boldsymbol{f}[\mathrm{Hz}] \\
\text { FEA }\end{array}$ & $\begin{array}{c}\Delta \boldsymbol{f} \\
{[\%]}\end{array}$ \\
\hline 1 & $1^{\text {st }} \mathrm{SF}$ & 60.1 & 64.4 & 7 \\
\hline 2 & $1^{\text {st }} \mathrm{NF}$ & 60.2 & 65.5 & 9 \\
\hline 3 & $1^{\text {st }} \mathrm{NF}$ & 60.4 & 65.5 & 8 \\
\hline 4 & $1^{\text {st }} \mathrm{NF}$ & 148.7 & 155.6 & 5 \\
\hline 5 & $1^{\text {st }} \mathrm{NF}$ & 151.0 & 155.6 & 3 \\
\hline 6 & $2^{\text {nd }} \mathrm{SF}$ & 193.7 & 190.7 & 2 \\
\hline 7 & $2^{\text {nd }} \mathrm{NF}$ & 204.4 & 215.0 & 5 \\
\hline 8 & $2^{\text {nd }} \mathrm{NF}$ & 207.3 & 215.0 & 4 \\
\hline 9 & $3^{\text {rd }} \mathrm{SF}$ & 304.7 & 307.8 & 1 \\
\hline 10 & $3^{\text {rd }} \mathrm{NF}$ & 333.1 & 346.7 & 4 \\
\hline 11 & $3^{\text {rd }} \mathrm{NF}$ & 335.9 & 346.7 & 3 \\
\hline 12 & $1^{\text {st }} \mathrm{ST}$ & 372.1 & 394.0 & 6 \\
\hline 13 & $1^{\text {st }} \mathrm{NT}$ & 382.5 & 425.2 & 11 \\
\hline 14 & $1^{\text {st }} \mathrm{NT}$ & 384.3 & 425.2 & 11 \\
\hline & & & & \\
\hline
\end{tabular}

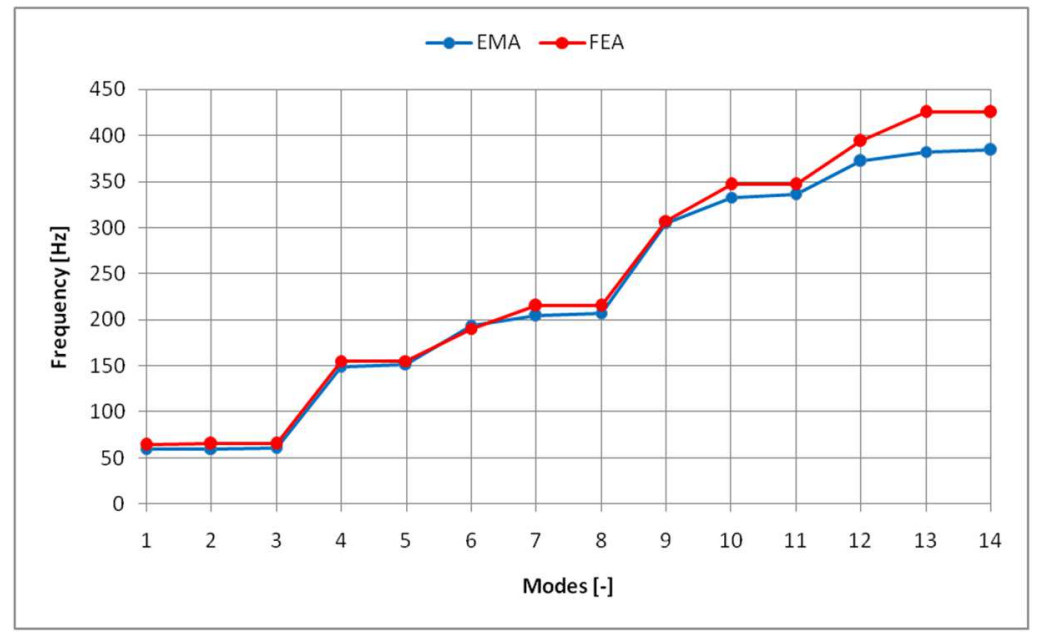

Fig. 4 Frequency comparison of aircraft propeller assembly

This FE model of propeller assembly was used as the standard for next performed analyses. All described analyses were set for 15 maximum modes to find and for limit search to minimum range from $0.1 \mathrm{~Hz}$. The first unlisted frequency was about $0.77 \mathrm{~Hz}$ and it represented longitudinal vibration of suspension spring only. Fig. 5 presents synchronous mode shapes of propeller (mode number 2, 7, 10 and 13) and Fig. 6 presents 
selected non-synchronous mode shapes of propeller (mode number 4, 8, 12 and 15). The deflections were visually greatly magnified and their referred values are normalized to the mass matrix, so they are not real.
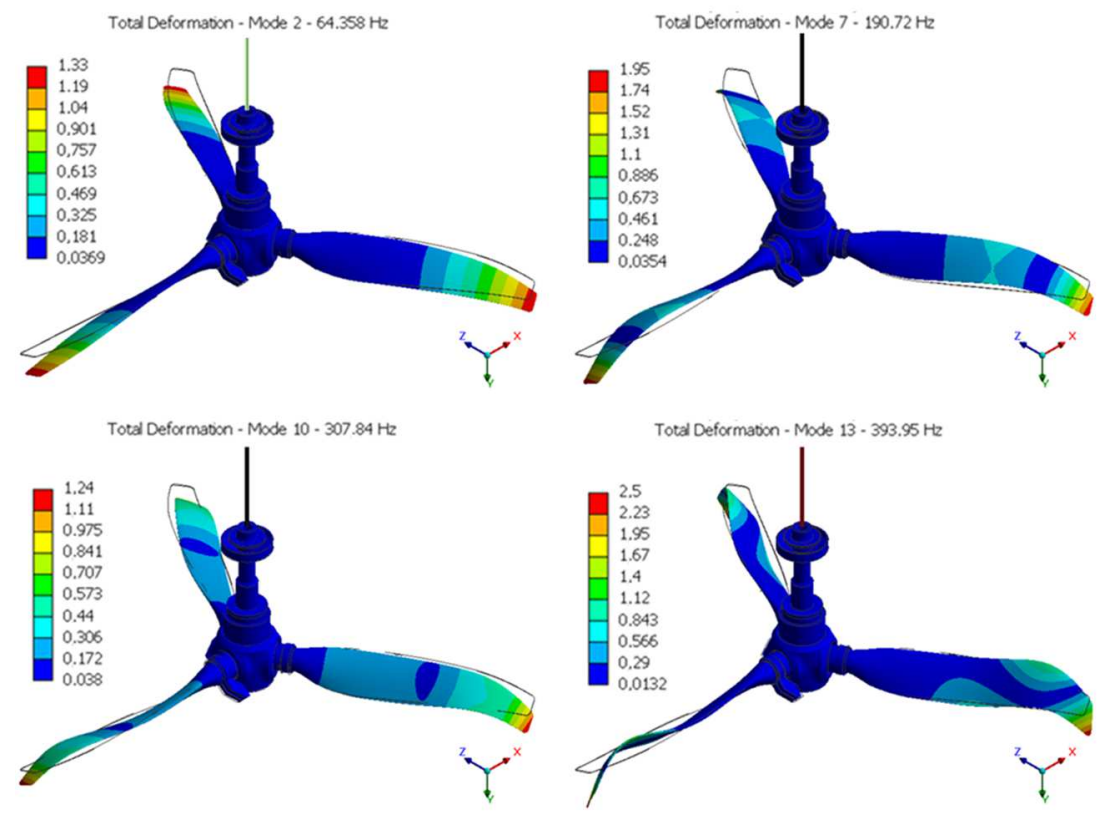

Fig. 5 Synchronous mode shapes of aircraft propeller assembly
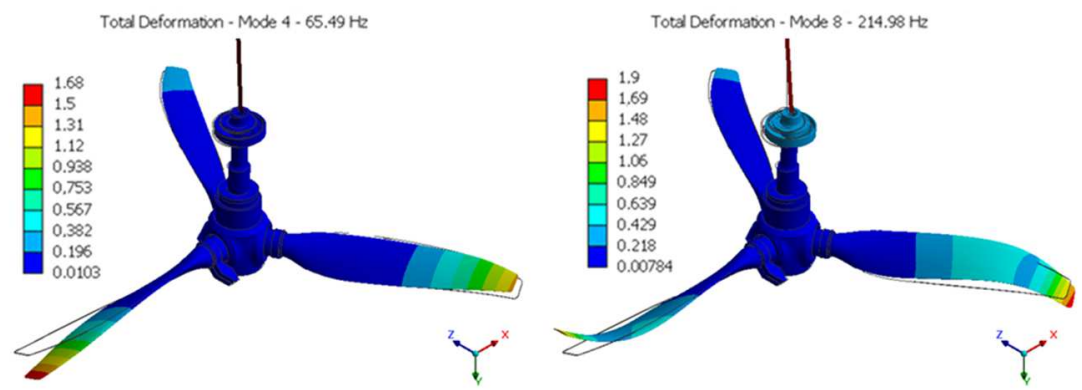

Total Deformation - Mode $12 \cdot 346.7 \mathrm{~Hz}$

Total Deformation - Mode $15-425.18 \mathrm{~Hz}$
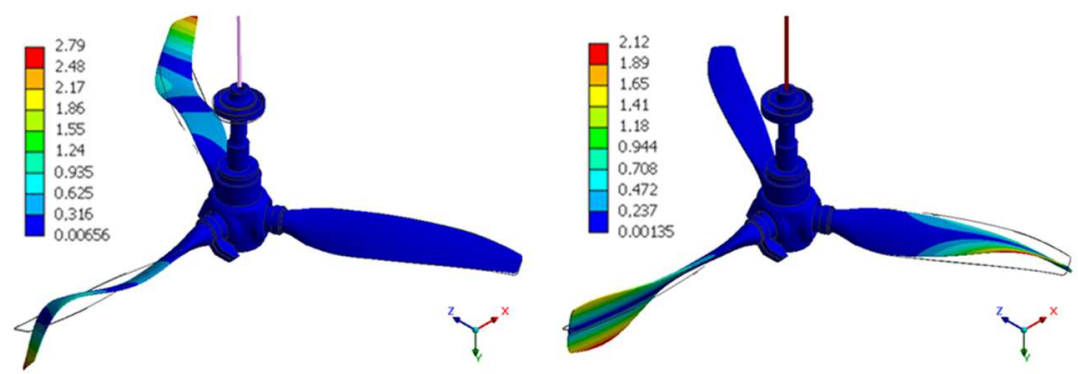

Fig. 6 Non-synchronous mode shapes of aircraft propeller assembly 
Tab. 2 represents participation factors and Tab. 3 represents effective masses. These tables were accessible in solution output. There are displayed values only for the first three modes. Global Cartesian coordinate system was located to the Centre of Gravity (CG) of propeller (see Fig. 1). It can be seen that the most effective mass for the mode shape is mainly in the direction of the $\mathrm{Y}$-axis, i.e., the axis of propeller rotation. This finding is not surprising, because the blades vibrate predominantly flexural in the $\mathrm{Y}$ direction with respect to the suspension system of the propeller. The torsion shapes around $\mathrm{X}$ and $\mathrm{Z}$ axes (rotation $\mathrm{RX}$ and RZ) occur until at higher frequencies. There is possible for better imagination to consider the propeller blade as simplified twisted cantilever beam with two plane of (minimum and maximum) stiffness. [1]

Tab. 2 Participation factor

\begin{tabular}{|c|c|c|c|c|c|c|c|}
\hline $\begin{array}{c}\text { Mode } \\
\text { No. }\end{array}$ & $\begin{array}{c}\boldsymbol{f} \\
{[\mathbf{H z}]}\end{array}$ & $\begin{array}{c}\text { Direction } \\
\mathbf{X}[\mathbf{1}]\end{array}$ & $\begin{array}{c}\text { Direction } \\
\mathbf{Y}[\mathbf{1}]\end{array}$ & $\begin{array}{c}\text { Direction } \\
\mathbf{Z}[\mathbf{1}]\end{array}$ & $\begin{array}{c}\text { Rotation } \\
\mathbf{X}[\mathbf{1}]\end{array}$ & $\begin{array}{c}\text { Rotation } \\
\mathbf{Y}[\mathbf{1}]\end{array}$ & $\begin{array}{c}\text { Rotation } \\
\mathbf{Z}[\mathbf{1}]\end{array}$ \\
\hline 1 & 64.5 & $5.71 \times 10^{-9}$ & $-2.46 \times 10^{-4}$ & $1.54 \times 10^{-8}$ & $-8.03 \times 10^{-9}$ & $-7.96 \times 10^{-9}$ & $-5.35 \times 10^{-8}$ \\
\hline 2 & 65.6 & $3.01 \times 10^{-9}$ & $1.17 \times 10^{-6}$ & $-5.98 \times 10^{-9}$ & $1.14 \times 10^{-8}$ & $-6.19 \times 10^{-8}$ & $-5.68 \times 10^{-8}$ \\
\hline 3 & 65.6 & $-8.04 \times 10^{-9}$ & $1.41 \times 10^{-7}$ & $3.12 \times 10^{-9}$ & $1.07 \times 10^{-8}$ & $3.44 \times 10^{-9}$ & $3.01 \times 10^{-9}$ \\
\hline
\end{tabular}

Tab. 3 Effective mass

\begin{tabular}{|c|c|c|c|c|c|c|c|}
\hline $\begin{array}{c}\text { Mode } \\
\text { No. }\end{array}$ & $\begin{array}{c}\boldsymbol{f} \\
{[\mathbf{H z}]}\end{array}$ & $\begin{array}{c}\text { Direction } \\
\mathbf{X}[\mathbf{k g}]\end{array}$ & $\begin{array}{c}\text { Direction } \\
\mathbf{Y}[\mathbf{k g}]\end{array}$ & $\begin{array}{c}\text { Direction } \\
\mathbf{Z}[\mathbf{k g}]\end{array}$ & $\begin{array}{c}\text { Rotation } \\
\mathbf{X}[\mathbf{k g}]\end{array}$ & $\begin{array}{c}\text { Rotation } \\
\mathbf{Y}[\mathbf{k g}]\end{array}$ & $\begin{array}{c}\text { Rotation } \\
\mathbf{Z}[\mathbf{k g}]\end{array}$ \\
\hline 1 & 64.5 & $3.26 \times 10^{-17}$ & $6.07 \times 10^{-8}$ & $2.36 \times 10^{-16}$ & $6.46 \times 10^{-17}$ & $6.34 \times 10^{-17}$ & $2.86 \times 10^{-15}$ \\
\hline 2 & 65.6 & $9.08 \times 10^{-18}$ & $1.36 \times 10^{-12}$ & $3.58 \times 10^{-17}$ & $1.31 \times 10^{-16}$ & $3.83 \times 10^{-15}$ & $3.23 \times 10^{-15}$ \\
\hline 3 & 65.6 & $6.47 \times 10^{-17}$ & $2.00 \times 10^{-14}$ & $9.74 \times 10^{-18}$ & $1.15 \times 10^{-16}$ & $1.18 \times 10^{-17}$ & $9.08 \times 10^{-18}$ \\
\hline
\end{tabular}

\section{Modal Cyclic Symmetry}

\subsection{Theory of Modal Cyclic Symmetry}

Many rotational parts of aero turbine engines include geometric characteristics, which are repeated about an axis of symmetry (e.g., bearings, discs, drums, impellers, gears, propeller's blades, shafts, etc.). There is possible to define the structure in terms of a single symmetric sector, which is repeated at equally spaced intervals about axis of symmetry. If the displacement boundary conditions of all sectors are identical with respect to the axis of symmetry. There is possible to analyze the full circular structure in terms of the mass and stiffness properties of a single symmetric sector. This technique was adapted from John M. Dickens (1980) and was called as Cyclic Symmetry Modelling (CSM). Its main advantage is elapsed time saving of extensive Central Processing Unit (CPU) and hardware demand reduction because model size is multiply lower. There is possible to obtain the natural frequencies and mode shapes of the entire structure for set range of nodal diameters of a single sector. Cyclic symmetry is implemented in ANSYS by defining constraint relationships between the high and low edges of basic sector. The edges may be of arbitrary shape. The basic sector is used twice to satisfy the 
required constraint relationship (Fig. 7). The definition of constraint equations depends on the specified harmonic index. A proper sector represents a pattern that, if repeated $n$ times in a cylindrical coordinate system, would yield the complete structure. There exist two modelling restrictions - the low edge sector angle must be less than the high edge sector angle and the nodes on the low and high edges must be coincident [2, 4-6].

The relationship between harmonic index $k$ and nodal diameter $d$ for a model consisting of $n$ sectors is given by the following equation:

$$
d=m \cdot n \pm k ; \quad m=0,1,2,3, \ldots .
$$
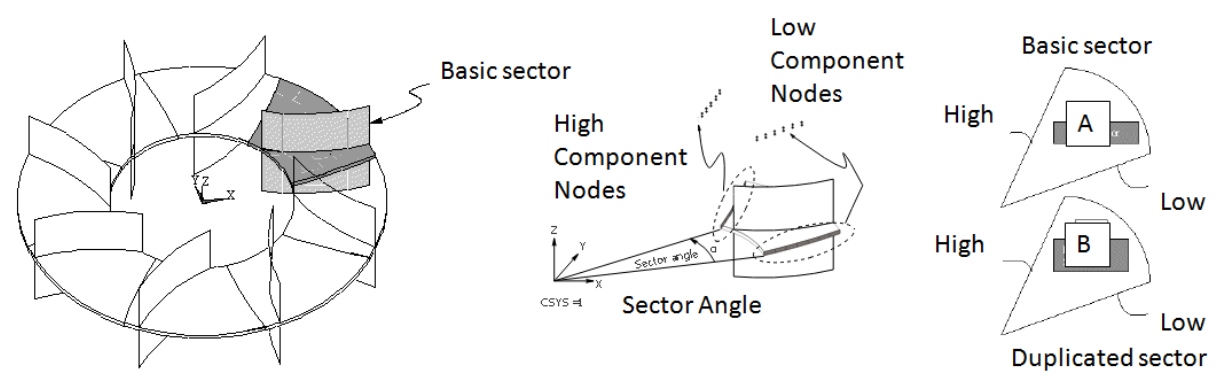

Fig. 7 Basic and duplicated sector of cyclic symmetry structure [6]

The harmonic index range is from 0 to $n / 2$ (or $(n-1) / 2$ if $n$ is odd). Sector model must be cyclically symmetric in any defined cylindrical system. The angle $\Delta \theta$ spanned by the basic sector should be according the $n=360^{\circ} / \Delta \theta$, where $n$ is an integer.

The displacement condition of cyclic symmetry structure is that the low edge displacement is transferred to the high edge displacement:

$$
\left\{\begin{array}{l}
u_{\text {high }}^{\mathrm{A}} \\
u_{\text {high }}^{\mathrm{B}}
\end{array}\right\}=\left[\begin{array}{cc}
\cos d \alpha & \sin d \alpha \\
-\sin d \alpha & \cos d \alpha
\end{array}\right] \cdot\left\{\begin{array}{c}
u_{\text {low }}^{\mathrm{A}} \\
u_{\text {low }}^{\mathrm{B}}
\end{array}\right\} .
$$

This equation is function of nodal diameter $d$, which generates various constraint equations for certain nodal diameter. By analyzing a single $120^{\circ}$ sector of a 3-blade aircraft propeller, there is possible to obtain the couple $360^{\circ}$ model solution via simple post processing calculations. Using twice the usual number of DOFs in this case, the single sector represents a $2 / 3$ part of the model. Procedure scheme for cyclic symmetry modal analysis in MAPDL (Mechanical ANSYS Parametric Design Language) is described in Fig. 8.

\subsection{Modal Cyclic Symmetry Analysis of Propeller Segment}

The aim of this analysis was to compare natural frequencies and mode shapes for two different geometries of segment. The segment represented third of complete propeller assembly with $120^{\circ}$ sector angle. The first type of segment (marked as A) was typical for cyclic symmetry modelling, where propeller blade was located in the middle of hub geometry. The second type of segment (marked as B) was untypical for its section plane choice, which cut propeller blade on two different parts. Both types of segment geometries with cyclic symmetry definition are presented in Fig. 9. 

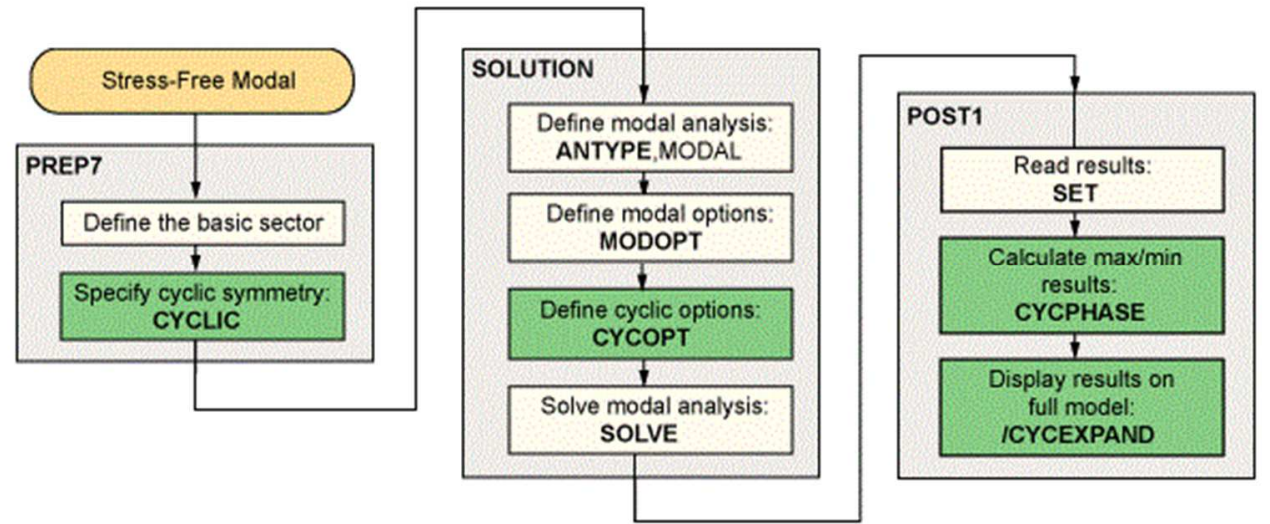

Fig. 8 Procedure for modal cyclic symmetry analysis [4]

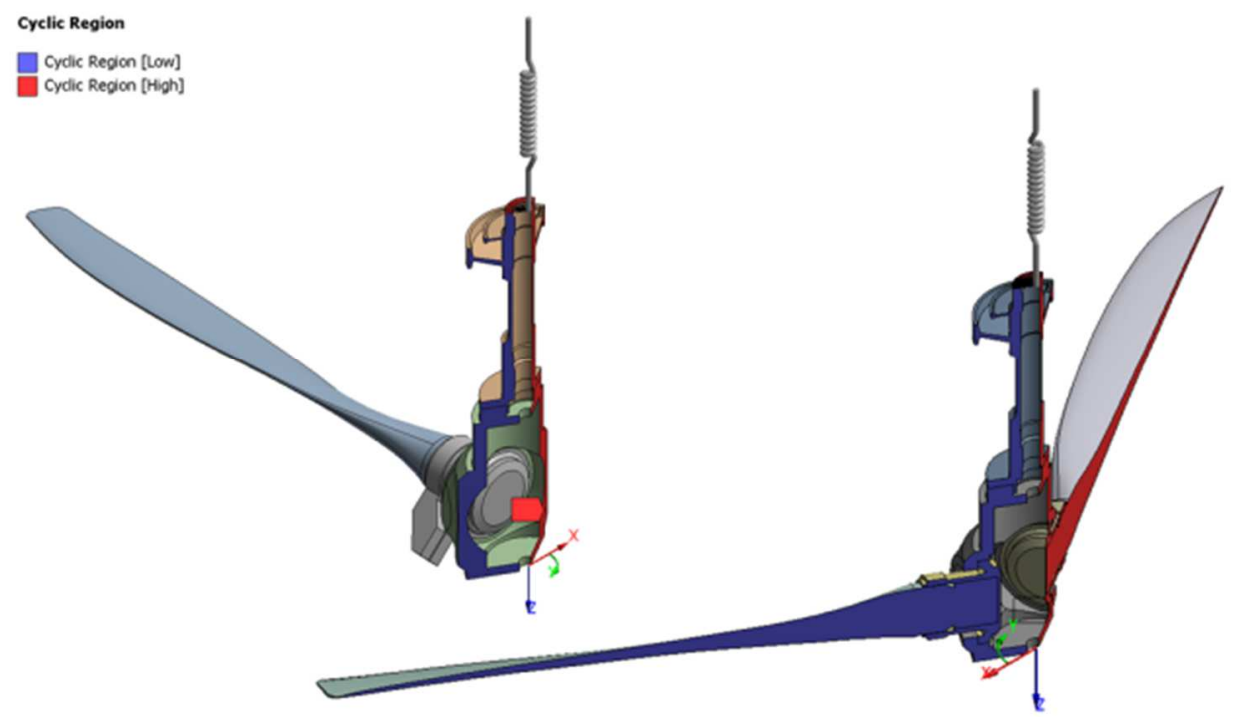

Fig. 9 Geometry of A and B cyclic symmetry segment

There was important to prepare the cutting of geometry correctly and defined the cyclic region with low and high face in the relation with cylindrical coordinate system in Mechanical Workbench. FE models of A and B segment were created similar as FE model of complete propeller assembly. Mesh of segment A contained 57935 nodes and 32581 elements. Mesh of segment B contained 64944 nodes and 33166 elements. View of both FE models is presented in Fig. 10. 


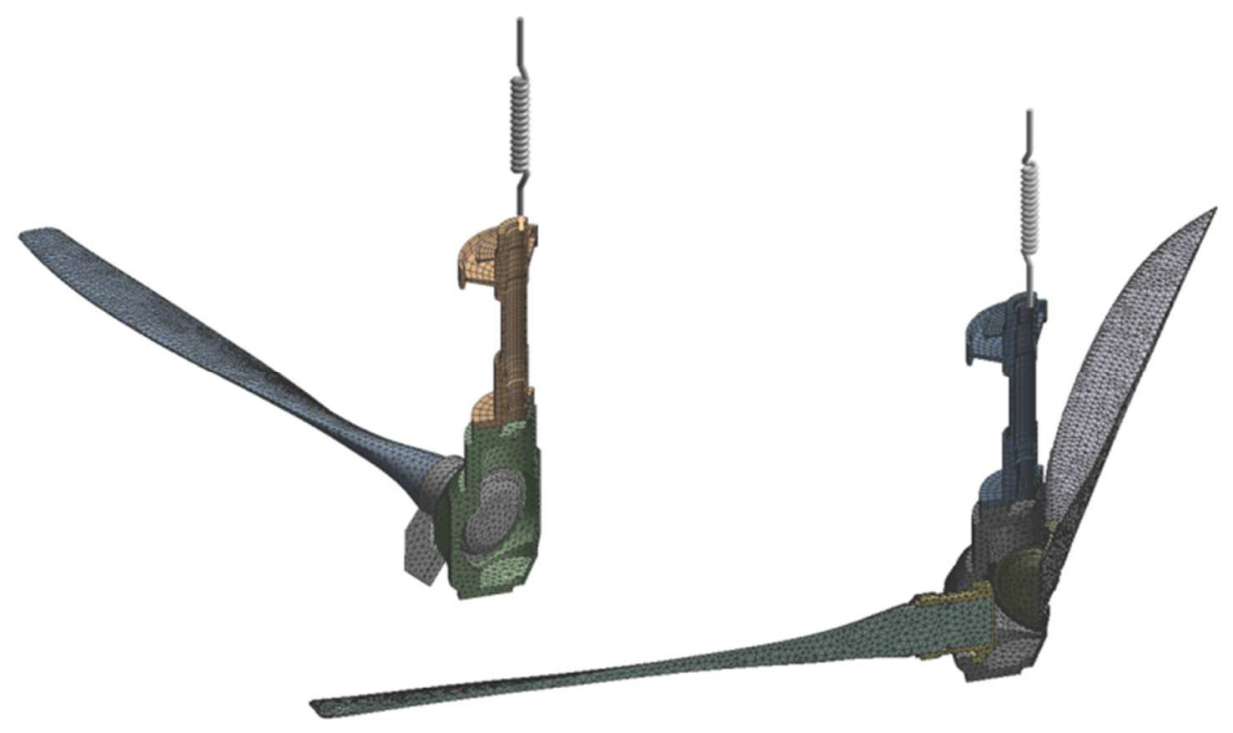

Fig. 10 FE model of A and B cyclic symmetry segment

\section{Component Mode Synthesis}

\subsection{Theory of Component Mode Synthesis}

Component Mode Synthesis (CMS) was developed with great contribution by Professor Roy R. Craig, Jr. in 1966, while he worked at the Boeing Company [7]. Thereafter, Craig and Bampton suggested Fixed Interface CMS method in 1968, which has put into the shade Guyan Reduction Procedure, from year 1965. Next development on this field brought Free Interface and Hybrid Interface method. A typical use of CMS involves modal analyses of large and complicated structural design such as airframe or aero engine.

CMS is a form of substructure coupling analysis, which performs a modal analysis of a structure based on independent modal analyses of its individual parts. The method includes making the components work together as a single structure by satisfying intercomponent compatibility and equilibrium constraints. CMS is explained widely in documents [8-15] with many practical examples.

The CMS method displaces the full model DOFs $\{u\}$ by a set of master or boundary DOFs $\left\{u_{\mathrm{m}}\right\}$ and a number of special mode coefficients $\left\{y_{\delta}\right\}$. This transformation is expressed as [2]:

$$
\left\{\begin{array}{l}
u_{\mathrm{m}} \\
u_{\mathrm{s}}
\end{array}\right\}=\boldsymbol{T} \cdot\left\{\begin{array}{c}
u_{\mathrm{m}} \\
y_{\delta}
\end{array}\right\} .
$$

Here $\boldsymbol{T}$ is transformation matrix for Fixed Interface method and it has this form:

$$
\boldsymbol{T}=\left[\begin{array}{cc}
I & 0 \\
\boldsymbol{G}_{\mathrm{sm}} & \phi_{\mathrm{s}}
\end{array}\right] .
$$


The constraint modes are here the displacements at the interior DOFs due to unit displacements of the boundary DOFs. These are expressed by matrix $\boldsymbol{G}_{\mathrm{sm}}$ :

$$
\left[\boldsymbol{G}_{\mathrm{sm}}\right]=-\left[K_{\mathrm{ss}}\right]^{-1} \cdot\left[K_{\mathrm{sm}}\right] \text {. }
$$

The normal (vibration) modes are here the mode shapes of the components with the fixed boundary DOFs and these are expressed by matrix $\phi_{\mathrm{s}}$.

The CMS assumes that the motion of slave or interior DOFs is approximated by a summation of the constraint modes and a subset of the normal modes of the components. This equation is valid for a particular mode:

$$
\left\{u_{\mathrm{s}}\right\}=\left\{u_{\mathrm{m}}\right\}\left[\varphi_{\mathrm{c}}\right]+\left\{y_{\delta}\right\}\left[\phi_{\mathrm{s}}\right] \text {. }
$$

The constraint mode shapes $\phi_{\mathrm{c}}$ and the normal mode shapes $\phi_{\mathrm{s}}$ are determined in the Generation Pass Process, $u_{\mathrm{m}}$ and $y_{\delta}$ are computed in the Use Pass Process and $u_{\mathrm{s}}$ is computed in the Expansion Pass Process. Procedure with applicable CMS solvers and files is hinted in Fig. 11.

\subsection{Component Mode Synthesis of Propeller Assembly}

The aim of this analysis was to show how perform implemented CMS in ANSYS MAPDL environment and to compare obtained results with next modal analyses, which were performed by another techniques. CMS is available in the Main menu in the Solution tree under the SE Management (CMS) title. This substructure analysis involves three distinct steps called passes (i.e., Generation, Use, Expansion). The operations are carried out using Manager window.

CMS procedure can be divided into several steps. The first step represented FE model building in ANSYS Mechanical Workbench. The preference was for better author's knowledge of this software. The second step included definition of element components and nodal interface components, which was realized through Named Selection option. After that the input file was generated and was launched subsequently in MAPDL environment. Fig. 12 presents all defined components in the Component Manager window. Nodal and element components are displayed in Fig. 13 and Fig. 14.

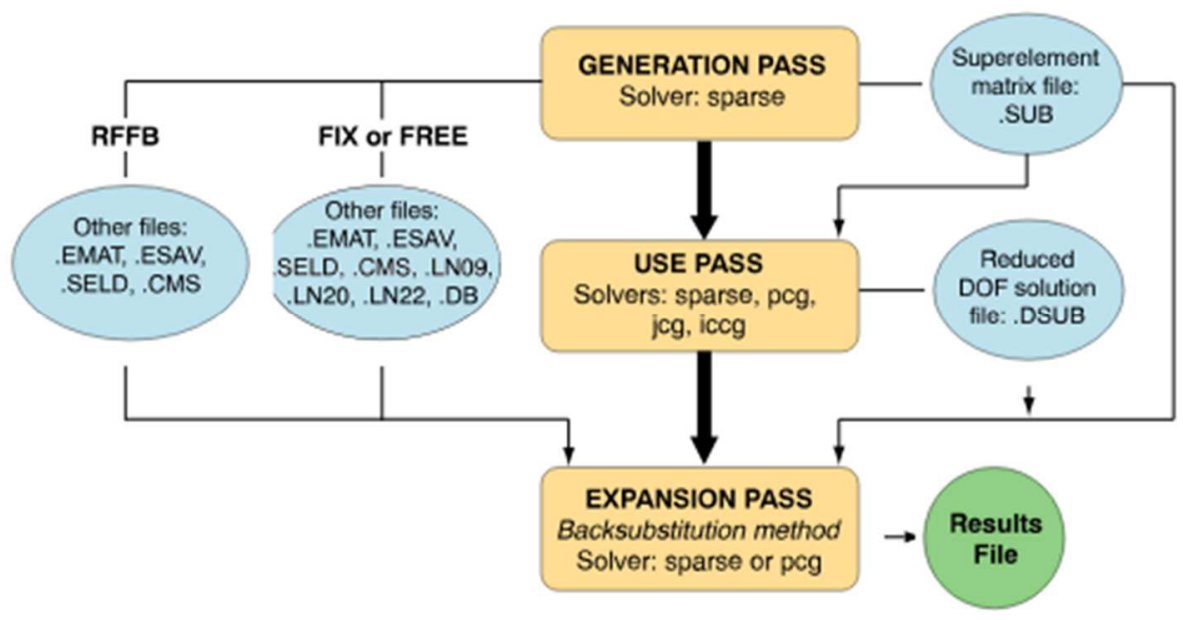

Fig. 11 CMS procedure in ANSYS [2] 


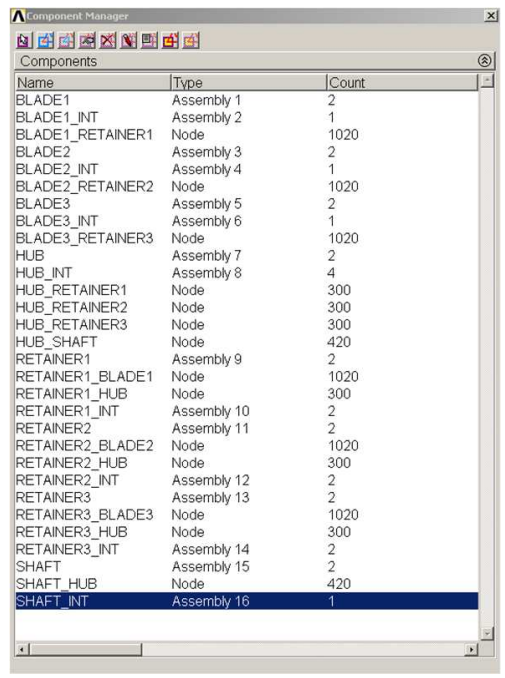

Fig. 12 All defined components in MAPDL (CMS)

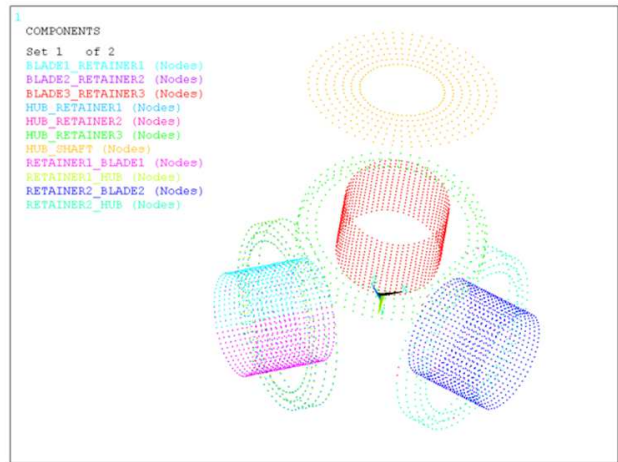

Fig. 13 Nodal components in MAPDL $(C M S)$

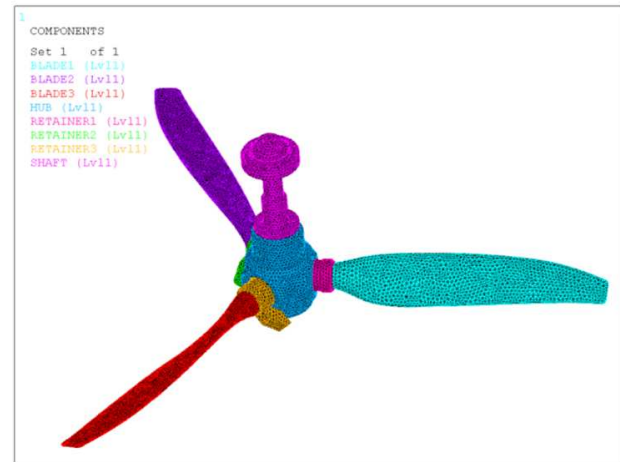

Fig. 14 Element components in MAPDL $(C M S)$

The third step represented Generation Pass Process, which generated Super Elements (SE) and Master DOFs. SE was matrix of condensed element group from predefined element component. Master DOF served as interface between SE and surrounding elements and was defined via interface nodes, which transferred loading. Master DOF was required only at interface nodes. There was used Interface Method option (Fixed or Free). The fourth step aggregated Use Pass, which involved modal analysis specification inclusive of modal extraction method setting. There were solved individual modal analyses of components in assembled substructure. The complete list of defined super elements is illustrated in Fig. 15.

The fifth step represented Expansion Pass, it meant that linear results from the master nodes were expanded to the slave nodes of the SE. The last sixth step constituted loading of component result files into the general postprocessor. Particular displacements can be plotted also in the Results Viewer application. The first flexural synchronous mode shape of propeller is presented in Fig. 16. 


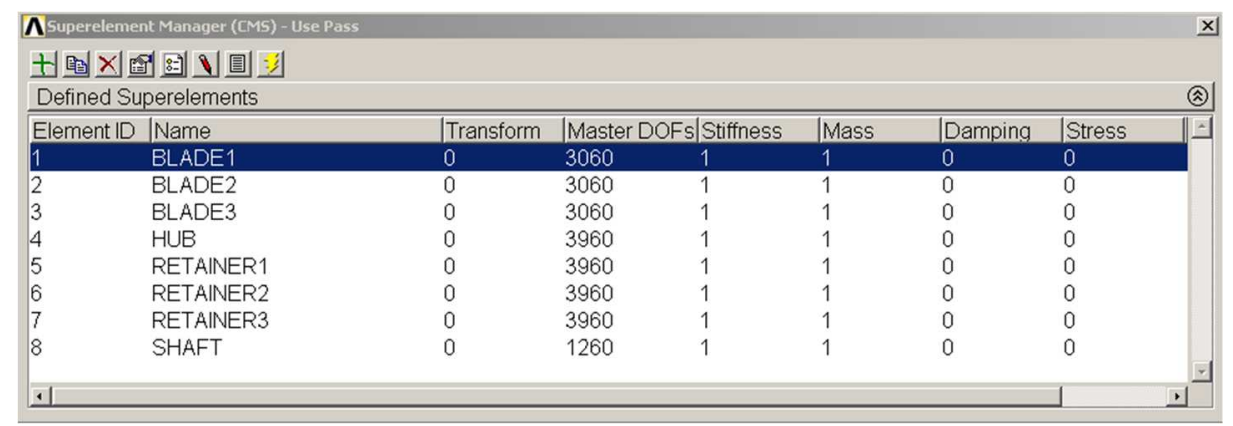

Fig. 15 Defined super elements in MAPDL (CMS)

\section{Discussion of Results}

The complete summary of computed results is presented in Tab. 4. There were compared frequencies of the tree different manners of modal computation. The column's numbering of table starts from left side. The column II represents FE model of propeller, where part connection was provided through bonded contact (standard). The column III represents also propeller assembly, where merged nodes were between contact surfaces of connected parts. The columns IV and V include two types of cyclic symmetry segments (A and B) and last two columns VI and VII represent CMS with used dissimilar Interface methods (Fixed and Free). The frequency differences are absolutely insignificant by sight, $2 \%$ maximum from the standard. The FE model of cyclic symmetry segment A was created fastest of all stated variants. The CMS model preparation was the most time-consuming at the other side. At the conclusion it can be said that compared techniques of FE model creation are equivalent in achieved accuracy of results. Nevertheless, it all depends on the size and complexity of analysed FE assembly (e.g., mesh influence) including necessary FE analyst's experience.

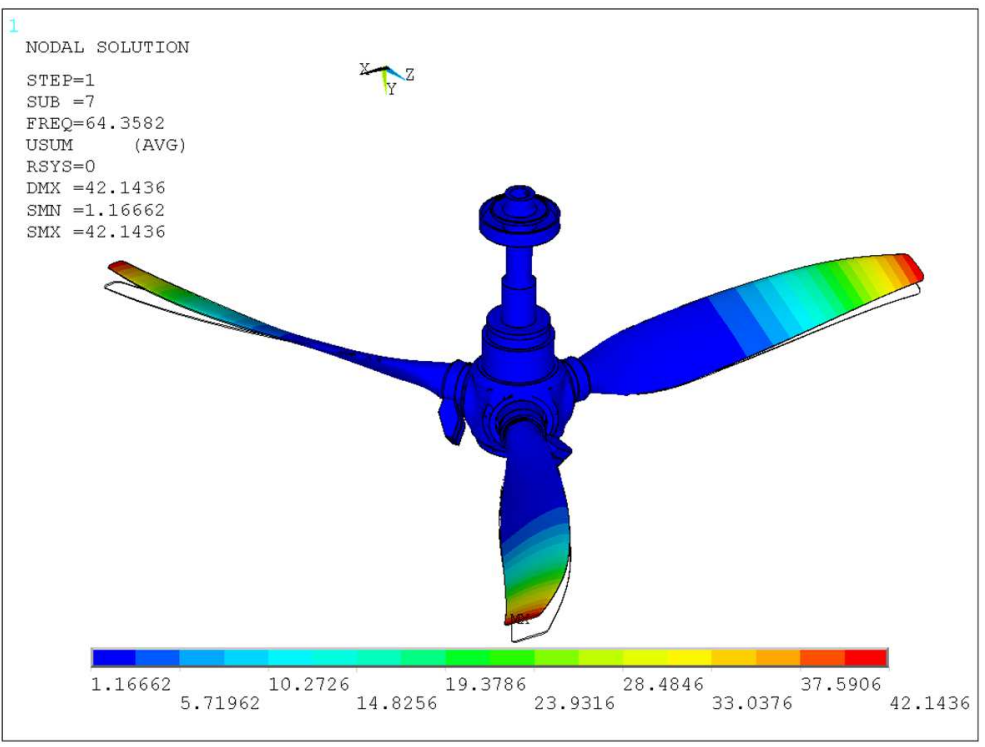

Fig. 16 The first mode shape of propeller (CMS) 
Tab. 4 Summary of results

\begin{tabular}{|c|c|c|c|c|c|c|}
\hline I & II & III & IV & V & VI & VII \\
\hline $\begin{array}{c}\text { Mode } \\
\text { No }\end{array}$ & $\begin{array}{c}f[H z] \\
\text { FE As- } \\
\text { sembly } \\
\text { Bonded } \\
\text { MPC }\end{array}$ & $\begin{array}{c}f[H z] \\
\text { FE As- } \\
\text { sembly } \\
\text { Merged } \\
\text { Nodes }\end{array}$ & $\begin{array}{c}f[H z] \\
\text { Cyclic } \\
\text { Sym- } \\
\text { metry } \\
\text { Segment } \\
\text { A }\end{array}$ & $\begin{array}{c}f[H z] \\
\text { Cyclic } \\
\text { Sym- } \\
\text { metry } \\
\text { Segment } \\
\text { B }\end{array}$ & $\begin{array}{c}f[\text { Hz] } \\
\text { CMS } \\
\text { Fixed In- } \\
\text { terface } \\
\text { Method }\end{array}$ & $\begin{array}{c}f[H z] \\
\text { CMS } \\
\text { Free In- } \\
\text { terface } \\
\text { Method }\end{array}$ \\
\hline 1 & 64.36 & 64.36 & 64.36 & 64.50 & 64.36 & 64.36 \\
\hline 2 & 65.49 & 65.48 & 65.49 & 65.63 & 65.49 & 65.49 \\
\hline 3 & 65.49 & 65.49 & 65.49 & 65.63 & 65.49 & 65.49 \\
\hline 4 & 155.56 & 155.51 & 155.54 & 157.64 & 155.56 & 155.56 \\
\hline 5 & 155.58 & 155.54 & 155.54 & 157.64 & 155.58 & 155.58 \\
\hline 6 & 190.72 & 190.70 & 190.73 & 191.72 & 190.72 & 190.72 \\
\hline 7 & 214.98 & 214.75 & 214.99 & 218.21 & 214.98 & 214.98 \\
\hline 8 & 215.00 & 214.94 & 214.99 & 218.21 & 215.01 & 215.00 \\
\hline 9 & 307.84 & 307.68 & 307.81 & 313.73 & 307.85 & 307.84 \\
\hline 10 & 346.69 & 346.50 & 346.73 & 348.74 & 346.69 & 346.69 \\
\hline 11 & 346.70 & 346.69 & 346.73 & 348.74 & 346.69 & 346.69 \\
\hline 12 & 393.95 & 393.89 & 393.94 & 395.53 & 393.96 & 393.95 \\
\hline 13 & 425.18 & 425.17 & 425.19 & 425.55 & 425.18 & 425.18 \\
\hline 14 & 425.18 & 425.18 & 425.19 & 425.55 & 425.18 & 425.18 \\
\hline
\end{tabular}

\section{References}

[1] HUJEČEK, Z. Study Modulus No.17 - Aircraft Propellers (in Czech). Brno: CERM, 2004. 96 p.

[2] Anon. Training manual - Dynamics - Release 8.1. Canonsburg: SAS IP, 2004. $150 \mathrm{p}$.

[3] VYSOKÝ, R. A Contribution to the Coupled Oscillation of a Small Turboprop Engine (in Czech) [PhD Thesis]. Brno: University of Defence, 2015. 104 p.

[4] ANSYS Mechanical APDL Technology Demonstration Guide. Canonsburg: ANSYS Inc., 2013. 654 p.

[5] Anon. ANSYS v7.1 Modal Cyclic Symmetry: Answers to Common Questions. Middlebury: CAE Associates, 2003. 73 p.

[6] Anon. Cyclic Symmetry Analysis. ANSYS 2002 Conference, C. A. Evolution, Mechanics and Simulation Support Development Group, 2003. 26 p.

[7] HEMEZ, F.M. Roy Craig, Engineering Educator and Pioneer Contributor to Component Mode Synthesis. In IMAC Conference, 2003. 12 p. 
[8] Anon. Analysis of Large Assemblies Using Component Mode Synthesis (CMS) Technique in ANSYS Workbench and MAPDL - Ask the Experts. Webinar. Canonsburg: ANSYS Inc., 2011.

[9] ANSYS Mechanical APDL Advanced Analysis Guide. Canonsburg: ANSYS Inc., 2013. $414 \mathrm{p}$.

[10] IMAOKA, S. Component Mode Synthesis in ANSYS Workbench Simulation. ANSYS Advantage, 2007, Vol. I, No. 3, p. 26-27.

[11] JAMES, S. Coupled Rotor-Housing Dynamics Using Component Mode Synthesis. Canonsburg: ANSYS Corporation, 2011. 20 p.

[12] RATH, R. Analysis of Large Assemblies Using Superelements in ANSYS Workbench. Canonsburg: ANSYS Inc., 2013. [cited 2013-09-11]. Available from: <www.ansys-blog.com/superelements>.

[13] RIXEN, D. Dynamic Substructuring Concepts - Tutorial. Delft: University of Technology, 2010. 59 p.

[14] THIEFFRY, P. Reduction Techniques, Part 2: Substructuring - Applicability and Examples. Canonsburg: ANSYS Inc., 2012. 22 p.

[15] ZUO, Y. and WANG, J. A Component Mode Synthesis Method for 3-D Finite Element Models of Aero-Engines. Journal of Mechanical Science and Technology, 2015, Vol. 12, No. 29, p. 5157-5166. 